\title{
Narrativas y debates acerca de la guerra y la paz en el África subsahariana
}

\author{
Narrativas e debates acerca da guerra e paz na África subsaariana \\ Narratives and debates about war and peace in sub-Saharan Africa
}

Diego Buffa*

María JoséBecerra*

\section{Resumen}

En este artículo nos proponemos poner a disposición del lector nuevas corrientes, debates y abordajes conceptuales - de una nutrida literatura vinculada a las ciencias sociales - que nos permitan comprender problemáticas capitales del África subsahariana, como lo son los conflictos intra-estatales, las emergencias políticas complejas, el intervencionismo humanitario y los procesos de paz, gestados durante la Posguerra Fría; portadores de inéditas lógicas y parámetros rectores. En tal sentido, pretendemos observar, a través de enfoques contrapuestos y en otros casos complementarios, diferentes aristas y perspectivas de complejas realidades al sur del Sahara.

Palabras claves: África subsahariana. Conflictos. Procesos de paz.
En este artículo procuramos realizar un análisis historiográfico de las diferentes concepciones teóricas referidas a la guerra y a la resolución de conflictos en el África Subsahariana. Los cambios en el sistema internacional desde el final de la disputa

* Director del Programa de Estudios Africanos del Centro de Estudios Avanzados de la Universidad Nacional de Córdoba, Argentina. Doctor en Relaciones Internacionales por la Universidad Nacional de Rosario, Argentina. Investigador y docente de posgrado en el Centro de Estudios Avanzados de la Universidad Nacional de Córdoba y en el Instituto de Relaciones Internacionales de a Universidad Nacional de La Plata, Argentina. E-mail: africa@cea.unc.edu.ar.

** Magister en Relaciones Internacionales por la Universidad Nacional de Córdoba, Argentina. Co-directora del Programa de Estudios Africanos del Centro de Estudios Avanzados de la Universidad Nacional de Córdoba, Argentina; y Coordinadora Académica de la Especialización en Estudios Afroamericanos de la Universidad Nacional de Tres de Febrero, Argentina. E-mail: estudiosafrcanos@hotmail.com.

Recebido em 18/12/2014 - Aprovado em 25/03/2015 http://dx.doi.org/10.5335/hdtv.15n.1.5277 
Este-Oeste, devinieron en una relectura de la manera de comprender la complejidad de las guerras, que ya no serán sólo enfrentamientos entre unidades soberanas y autónomas -los Estados-, sino que de manera abrumadora se proyectarán como conflictos bélicos de carácter intra-estatales, con movimientos rebeldes cuyo objetivo principal no se orientará a la toma del poder estatal. En otras palabras, las guerras westfalianas, cuyo objeto era el Estado, sus objetivos la supervivencia y el aumento del poder del mismo, de carácter inter-estatales y realizadas entre enemigos políticos, seden el paso a un nuevo tipo de guerras donde la población civil será la principal víctima de estos conflictos, mucho más imbricadas en su lógica, de carácter mayoritariamente intra-estatal, enfrentando a las fuerzas estatales a enemigos despolitizados o, en otras ocasiones, criminalizados.

El nuevo carácter y complejización de los conflictos subsaharianos, devino también en nuevas estrategias de paz, desplegadas por una multiplicidad de actores, y reflejada desde la academia a través de enfoques, categorías y conceptualizaciones que intentan dar cuenta de estos cambios instrumentalizados en los procesos de resolución de las contiendas.

Como ya señalamos, el fin de la disputa Este-Oeste nos propone un punto de inflexión en el capital estratégico con que los Estados poscoloniales subsaharianos habían contado hasta aquel momento. Como correlato de ello, asistiremos a una abrupta cancelación de prebendas o "contratos de mantenimientos" - propiciados hasta entonces por las dos superpotencias mundiales en la búsqueda de garantizar lealtades y consolidar sus respectivas áreas de influencia en el África subsahariana - a lo que se le sumo, la paulatina desfinanciación de la subregión desde los años 80, producto de la crisis de la deuda y la fatiga de los donantes, las condicionalidades impuestas desde los Organismos Financieros Internacionales, entre otras variables exógenas, contribuyendo a alterar el espacio subregional estimulando el colapso y las tensiones hacia el interior de un numero sin precedentes de Estados subsaharianos en las últimas tres décadas. Por otra parte, lo que algunos autores han dado en llamar "la maldición de los recursos", inscripta en un mundo globalizado, afectó a la subregión profundizando la pérdida de soberanía estatal, la reformulación de redes clientelares, la intromisión de nuevos actores externos e internos y la construcción de un discurso justificador de la violencia, vinculado a la avaricia (greed) y el agravio (grievance), plasmado en la narrativa de las nuevas guerra y la economía política de la guerra (BECERRA, 2006). Frente al nuevo carácter de los conflictos intra-estatales y las emergencias políticas complejas - entendidas como la conjunción de diversos elementos causales tales como el desmoronamiento de la economía formal y de las estructuras estatales, los conflictos civiles, las hambrunas, las crisis sanitarias, el éxodo de la población, etc. - los procesos de paz y el intervencionismo humanitario, en estas últimas décadas, irán tornándose también mucho más complejos, por la heterogeneidad de los actores intervinientes, el carácter de los incentivos ofrecidos a los 
bandos en pugna con el propósito de arribar a una paz duradera, y el accionar y los objetivos de lo que se ha dado en llamar el complejo de paz liberal, que sin duda alguna perfiló una nueva agenda internacional de construcción de la paz, bajo el paraguas del cosmopolitismo como paradigma hegemónico (BUFFA, 2010).

Todas estas transformaciones, no han pasado desapercibidas para una, cada vez mayor, literatura emanada desde las ciencias sociales que intentan a través de la construcción de nuevas categorías conceptuales -de manera crítica, complementando a veces y en otras ocasiones poniendo en tela de juicio los relatos predominantes hasta entonces-, comprender los profundos cambios acaecidos, abandonando explicaciones monocausales y reduccionistas, en la búsqueda de reflejar con mayor agudeza el entramado complejo de los procesos, el relacionamiento de sus protagonistas, sus estrategias, discursos, niveles de institucionalización, anclaje social de los actores y sus políticas, etc. En tal sentido, nos proponemos visualizar en este artículo, a partir de una labor analítica, distintas narrativas que intentan conceptualizar las trasformaciones en los conflictos y sus resoluciones en el África subsahariana a partir de un nuevo escenario internacional surgido en las postrimerías del siglo $\mathrm{XX}$, identificando sus principales referentes, sus abordajes cognitivos y eventuales puntos de contacto o disidencias.

\section{Nuevos relatos para comprender los conflictos en el Africa Sahariana}

Para autores como Chopra y Weiss, la visibilización de los conflictos periféricos como potencialmente causantes de intersticios de desestabilización y crisis global, generó un cambio de la agenda internacional. Cambio, objetivado en un abandono por parte de la comunidad internacional del principio de no injerencia en el ámbito de la soberanía de los Estados nacionales, a favor de un nuevo precepto anclado en el intervencionismo humanitario. El consenso necesario para privilegiar los imperativos humanitarios, sobre el resguardo de las jurisdicciones internas estatales, se fundamentó en la idea rectora de que las situaciones de colapso y conflicto intra-estatales, en la periferia, son atribuibles a la ineficacia de los gobiernos locales para garantizar el bienestar de su pueblo (CHOPRA; WEISS, 1992). En tal sentido, hay quienes aseguran que "desde el fin de la Guerra Fría, los Estados débiles y fallidos se han convertido en el problema más importante para el orden internacional" (FUKUYAMA, 2004).

Una nueva narrativa, enmarcada en el cosmopolitismo liberal y surgida al calor de esta reestructuración de la agenda internacional, contribuyó a legitimar desde su discurso, el intervencionismo humanitario, bajo la argumentación de que los derechos humanos en un contexto impregnado por la globalización no pueden ser constreñidos al ámbito nacional-estatal, sino que éstos deben ser contemplados a través de un prisma que eluda su antiguo corsé Estado-centrico para redireccionar su atención hacia la sociedad 
civil y particularmente en la conculcación de sus derechos y garantías, durante situaciones de emergencias politicas complejas (BADIE, 2004). Es decir, la ciudadanía universal $\mathrm{y}$ los derechos humanos se convirtieron en un componente central de su discurso moral, legitimando con ello desde las "guerras éticas" hasta, en sus versiones más exacerbadas -y al mismo tiempo reprochables-, del "humanismo civilizador".

En los últimos años, de manera mayoritaria, encontramos tres líneas argumentativas que intentan explicar el nuevo período alumbrado a partir de la Posguerra Fría en los conflictos subsaharianos. La primera corriente de análisis considera que la causa y perpetuación de los conflictos bélicos en África subsahariana está fuertemente determinada por el subdesarrollo de los países de la subregión. Es decir, resalta las condiciones estructurales de dependencia exterior, deuda externa, su status marginal en la economía mundial, entre otras. Dicho discurso, nos permite visualizar una parte de nuestro problema "los condicionantes estructurales que gestan y perpetúan los conflictos armados en la periferia". En dicho diagnostico han coincidido tanto neomarxistas como cooperantes para el desarrollo. No obstante, mientras que los primeros propician una desconexión que suprima las tenciones estructurales a través de un crecimiento autocentrado (AMÍN, 1994); los segundos promoverán la ayuda y la cooperación para el desarrollo como herramienta viabilizadora de la pacificación de los conflictos. Estos últimos, sostienen la idea de que la descomposición de los Estados, objetivada en función de las tensiones intra-estatales, forma parte intrínseca de la llamada "patología del subdesarrollo" y que para revertirla es necesario implementar una estrategia de intervención integral que actúe sobre el trinomio Paz-Desarrollo-Democracia (DOORNBOS, 2002, p. 5).

Una segunda corriente dentro de la literatura académica, pero al mismo tiempo fuertemente arraigada en el discurso de los mass media, tuvo un marcado impacto estigmatizante, particularmente en los conflictos subsaharianos. Esta literatura, fomenta la creencia de que las soluciones a los mismos solamente pueden proceder desde el ámbito internacional, dada la propia lógica de reproducción que éstos despliegan. En consonancia con ello, sus principales referentes, describen a los conflictos subsaharianos durante la Posguerra Fría bajo el epíteto del nuevo barbarismo (KAPLAN, 1994; RICHARDS, 1996). Dicha visión define a los conflictos inscriptos en la subregión africana, como nihilistas, anárquicos, salvajes e irracionales. Al mismo tiempo, esta lectura esencialista de la realidad, fija su atención de manera unicausal en torno a la etnicidad, a través de un discurso de índole racial, aferrado a determinismos bioculturales. El nuevo barbarismo, señalará Ruiz-Giménez, tiende a naturalizar las identidades étnicas entendiéndolas como primarias, innatas e irracionales cuando, en su opinión, son construidas social e históricamente. Por otra parte, este discurso explica los conflictos y la violencia por la mera existencia de diferentes e irreductibles identidades étnicas, religiosas o culturales. Ello oscurece el carácter dinámico, multifacético e interactivo de las identidades étnicas, así como la capa- 
cidad de muchos grupos étnico-culturales de convivir pacíficamente en gran parte de África y del mundo. $Y$, sobre todo, oculta la actuación y responsabilidad de diferentes actores y grupos sociales -africanos e internacionales- que, en su lucha por el poder y los recursos, instrumentalizan las identidades etnoculturales para movilizar a la población (RUIZ-GIMÉNEZ ARRIETA, 2002). ${ }^{1}$

Esta mirada decimonónica reeditada en las postrimerías del siglo $\mathrm{XX}$, presenta a los conflictos africanos bajo un cristal fatalista, asociados a un estado natural prepolítico hobbesiano y movilizados más por las pasiones que por la razón. La violencia sin sentido es un rasgo de las culturas de otros pueblos: donde ellos son violentos, pero nosotros somos pacíficos, y donde centrarnos en su degradación fácilmente se convierte en otra forma de celebrar y confirmar nuestro status superior, potenciando la necesidad de intervenir en ellos por parte de la comunidad internacional. Asimismo, reforzando de este modo la idea de que el mundo está, de hecho, dividido entre lo moderno y lo premoderno, donde lo moderno hace cultura, pero lo premoderno vive con una cultura eterna (MAMDANI, 2003, p. 58).

Una tercera corriente explicativa es la de las nuevas guerras, la cual nos facilita ahondar sobre variables analíticas no abordadas por los primeros planteos. Las nuevas guerras, enmarcadas durante el período de la Posguerra Fría, nos posibilitan observar con una nueva lente, la lógica de los conflictos armados intra-estatales, en la periferia del sistema internacional. Aunque Mary Kaldor, una de las principales referentes y acuñadora del término nuevas guerras, las circunscri- be al África y a Europa del Este (KALDOR, 2001), otros investigadores las localizan en el antiguo Tercer Mundo (SINGER, 1996), el mundo poscolonial (HOLSTI, 1996), o en la periferia del sistema internacional (SNOW, 1996). La caracterización que Kaldor hace de las nuevas guerras se basa fundamentalmente en dos aspectos. El primero de ellos lo funda, en la percepción de que tras el fin de la Guerra Fría asistimos a una explosión de conflictos armados de carácter interno que vienen a revertir el anterior predominio de las guerras interestatales. En segundo lugar argumenta, la apreciación de estos conflictos como radicalmente diferentes de las guerras precedentes, implicando este nuevo escenario un desdibujamiento de las distinciones entre guerra - entendida hasta entonces, como la violencia por motivos políticos entre Estados o grupos políticos organizados -, crimen organizado - como la violencia por motivos particulares, en general el beneficio económico, ejercida por grupos organizados privados- y violaciones a gran escala de los derechos humanos - es decir, la violencia contra personas individuales ejercida por Estados o grupos organizados políticamente (KALDOR, 2001, p. 16).

Circunscrito el análisis de las nuevas guerras al interior de los Estados, nos permite visualizar parámetros racionales por los cuales actuaron los principales actores locales de una contienda armada, proporcionándonos de este modo herramientas de comprensión, sin duda más analíticas de las que nos ofrecen otros abordajes. ${ }^{2} \mathrm{El}$ incremento de la violencia en los conflictos, el gestionamiento del caos tanto por parte del Estado como por parte de los rebeldes, y de 
la gestación de los discursos de "avaricia" (greed) versus "agravio" (grievance), constituyen tópicos medulares en la literatura de las nuevas guerras. Paul Collier, sostiene que la principal variable explicativa de las nuevas guerras no radican en los "agravios" (grievances) políticos o de otra naturaleza provenientes del Estado, sino más bien de la "avaricia" (greed) de los insurgentes, es decir, sus deseos de obtención de ganancias por la explotación de recursos naturales allí donde estos son abundantes (COLLIER, 2000, p. 95-101). No obstante en opinión de Christopher Cramer, el énfasis excesivo en la "avaricia" (greed) oscurece, en primer lugar, la existencia de importantes "agravios" (grievances) en la génesis de la violencia, vinculada a los procesos de exclusión social y política llevados a cabo durante años por algunos regímenes africanos (CRAMER, 1999, p. 14). Como señalan diversos autores, no se puede explicar la violencia armada como una mera lucha por recursos naturales, sino que ella está íntimamente conectada a las prácticas depredadoras y excluyentes de muchos regímenes africanos. En efecto, en muchas ocasiones es el propio orden estatal quien genera la violencia, marginando y hostigando a parte de su población, como bien lo ejemplifican los casos de Ruanda o de Burundi. ${ }^{3}$ En otras ocasiones, se trata de la respuesta de rechazo de algunos grupos sociales a los "agravios" producidos por un orden estatal considerado injusto y represor (ELLIS, 2004). En tal sentido la mera criminalización de los rebeldes, no contribuye a comprender en toda su magnitud las motivaciones de los actores armados, así como tampoco a pro- pender a develar las tensiones que originaron el conflicto (KEEN, 2000, p. 30-40).

$\mathrm{El}$ auge de las nuevas guerras y su perpetuación, en el continente africano, aparece íntimamente vinculado a cuatro factores que las promueven: el creciente peso en África de la economía informal y de la patrimonialización del Estado; el debilitamiento y colapso de numerosos Estados; el recurso a la violencia organizada por los actores sub-estatales como mecanismo para la explotación de recursos y la acumulación económica; y la globalización y desregulación económica, que facilita a los líderes locales su conexión, al margen del control estatal, con redes globales de compra de armas, transferencia de capitales, etc. Así pues, las nuevas guerras presentan algunas peculiaridades respecto a guerras de insurgencia de décadas anteriores. En primer lugar, son guerras con un fuerte componente económico, consistente en una "instrumentalización de los recursos en un sistema social patrimonial". En segundo lugar, se manifiestan como "esencialmente internas en su carácter y regionales en su dinámica", pues están mucho más vinculadas que las guerras previas a la economía informal regional e incluso a las redes delictivas de la economía global. Por último, dadas las características anteriores, se trata de guerras menos dependientes del patronazgo de actores externos, por lo que estos tendrán más dificultades para incidir en la marcha del conflicto (CILLIERS, 2000, p. 2, 5, 16-17).

Simultáneamente, la economía política de la guerra, concepto íntimamente ligado a las nuevas guerras, ayuda a visualizar cómo los actores intra-estatales, a partir de cierto 
momento del conflicto, reconfiguraron sus motivaciones iniciales. Motivaciones que cada vez más resultan suplidas, por el peso que adquiriere una agenda impregnada de razones económicas, justificadora de la persistencia de los conflictos (CILLIERS, 2000).

Frente a la clausura de un financiamiento externo, que supo actuar como principal sostén material, de los conflictos armados en el África subsahariana a lo largo de la Guerra Fría, la economía política de la guerra, nos allana el camino para centrar nuestra atención en las nuevas estrategias implementadas por parte de los actores en pugna para afrontar la crítica coyuntura. Circunstancia que, en algunos casos implicó el ocaso de conflictos intra-estatales de larga trayectoria, mientras que otros encontraron en la economía de la guerra la posibilidad de consolidarse y perpetuarse, los ejemplos de Mozambique y Angola, respectivamente, son paradigmáticos al respecto.

Por otra parte, no quisiéramos dejar de mencionar, aunque sea de manera tangencial, el hecho de que los conflictos armados africanos -en las últimas décadas- han generado de manera compulsiva el desarraigo de millones de desplazados, el alumbramiento de centenares de campos de refugiados y el despliegue de diversas estrategias de contención por parte de una multiplicidad de actores involucrados formales e informales, locales e internacionales. De acuerdo con lo expresado por Maria Serrano Martín (2012), diferentes narrativas referenciaron a los refugiados como héroes, víctimas o criminales. En tal sentido la autora hace referencia a un discurso "romántico", otro de carácter "humanitarista", y un tercero asociado a la "seguridad", donde cada uno de ellos, en diferentes momentos, proyectará diferentes políticas de asilo por parte de los estados africanos y el sistema internacional. ${ }^{4}$ En tal sentido, los diferentes discursos y tratamientos nos permite reconocer, no solo como la comunidad internacional y los principales actores locales estructuran su accionar en función de parámetros cambiantes a lo largo del tiempo, sino como estos se convierten en una variable que no podemos soslayar a lo hora de analizar el carácter, y las complejas formas de reproducción y perpetuación de los conflictos armados africanos. ${ }^{5}$

\section{El entramado complejo de los procesos de paz bajo un nuevo escenario normativo}

Ahora bien, cuando hablamos de resolución de conflictos nos referimos a iniciativas nacionales, internacionales, o de ambas instancias conjuntas de mediación, conducentes a conseguir la paz en situaciones de conflicto.

La participación externa en la resolución de los conflictos, durante los primeros años de la década del 90, se manifestó a través de múltiples estrategias. Especial atención le otorgaron los investigadores a lo que han dado en llamar: los dividiendo de la paz. Es decir, una serie de prebendas y beneficios económicos que la comunidad internacional ofreció a los contendientes del conflicto, a modo de persuadirlos sobre las ventajas de la paz (FRERKS, 2006). Estimulando su convencimiento de que los beneficios de la 
paz serían superiores que los obtenidos hasta entonces mediante la guerra.

Un segundo aspecto vinculado a la resolución de los conflictos está emparentado a la irrupción de, lo que autores como Mark Duffield llama, el complejo de paz liberal. Integrado por una pluralidad de actores internacionales -tales como las Naciones Unidas, organismos financieros internacionales, organizaciones regionales, Estados y agencias de donantes, organizaciones no gubernamentales, entre otras- a través de su multifacético accionar busca imponer como principio rector la condicionalidad de la ayuda como herramienta que le permita desalentar la prosecución de los conflictos (DUFFIELD, 2004).

La gestación de este complejo de paz liberal está íntimamente asociada a las trasformaciones en la resolución de controversias que experimentaron las misiones de las Naciones Unidas a partir de la finalización de la disputa Este-Oeste. Las típicas Operaciones de Mantenimiento de la Paz clasificadas como peacekeeping, vieron transformados sus mandatos a partir de lo que denominamos como la edad de oro de la diplomacia humanitaria correctiva, mediante lo que se conoció como "la agenda para la paz de Boutros-Ghali". Las peacekeeping operations, de orden disuasivo, restringidas a garantizar el alto el fuego -previamente acordado por las partes- $\mathrm{y}$ con un mandato de uso de la fuerza armada limitado a la legítima defensa, dieron paso a una nueva modalidad mucho más abarcativa y polifacética. Las nuevas peacebuilding operations, no se dedicaron sólo a supervisar el alto el fuego como las anteriores, sino que también se ocuparon del desarme, desmovilización y reintegración de combatientes, desminado, reparación de infraestructuras, distribución de ayuda humanitaria, reasentamiento de refugiados y desplazados, supervisión de elecciones, reforma del Estado, etc. Tuvieron, por tanto, un carácter multifuncional y una dinámica inclusiva de otros actores externos, en el sentido que implicaron una estrategia de intervención integral destinada a consolidar el proceso de paz y la reconstrucción del Estado. ${ }^{6}$

Autores como Roland Paris, crítico del accionar del complejo de paz liberal en la reconstrucción de los Estados post conflictos, nos advierte que a través de su accionar, solo se promovió de manera unívoca la implantación de un modelo restringido vinculado a democracias de mercado occidentales (PARIS, 1997, p. 56). En otras palabras, las estrategias de pacificación y reconstrucción de los Estados en conflictos implementadas por parte de la comunidad internacional no supieron o no quisieron incluir e integrar dinámicas o tradiciones políticas y socio-económicas locales, sino que de forma unilateral buscaron imponer la conformación de Estados "externalizados", con democracias de baja intensidad y economías neoliberales.

Por otra parte, desde mediados de la década del 90, podemos advertir una fuerte apuesta por parte del complejo de paz liberal por potenciar el papel de las organizaciones regionales en el ámbito de la "construcción de la paz". Este cambio discursivo que proponía misiones de carácter Sur-Sur y apuntaba a "soluciones africanas para problemas africanos", supo reflejar un retraimiento 
de la euforia por la diplomacia humanitaria coercitiva de los países occidentales, al mismo tiempo que una crisis institucional en la que Naciones Unidas se veía sumida -desbordada por tantas misiones, pero también afectada e incluso en ciertos aspectos paralizada por los fracasos ocurridos en las operaciones de Somalia o Ruanda - (RUIZ-GIMÉNEZ ARRIETA, 2011, p. 262). En sintonía con ello, muchas organizaciones regionales transformaron sus mandatos y funciones en el ámbito de la paz y seguridad, en la búsqueda de un mayor protagonismo y liderazgo en los procesos de pacificación africanos. Predecesora en este campo, la Comunidad Económica de los Estados del África Occidental (CEDEAO), a través de su Grupo de Verificación de la Cesación del Fuego (ECOMOG por sus siglas en inglés) intervino en Liberia (1990-1997), Sierra Leona (1991 y 1998), Guinea-Bissau (1999) y Costa de Marfil (2003). Por su parte, la Comunidad para el Desarrollo del África Austral (SADC) intervendría en Lesotho (1997) para desarticular un golpe de Estado (RUIZ-GIMÉNEZ ARRIETA, 2011, p. 263). Acorde con las nuevas directrices esgrimidas por la comunidad internacional en estas últimas décadas, en lo atinente a la paz y seguridad -y aun mayor involucramiento de los africanos en los conflictos y sus resoluciones desplegados en su propio escenario regional-, la sucesora de la Organización para la Unidad Africana (OUA) orientará su accionar conforme al nuevo escenario normativo, mediante el alumbramiento de una Arquitectura Africana de Paz y Seguridad (APSA). En tal sentido, la Unión Africana (UA) impulsó el derecho a intervenir ${ }^{7}$ en situaciones que "representen una amenaza al orden legítimo para restaurar la paz y la estabilidad en un Estado miembro basado en las recomendaciones del Consejo de Paz y Seguridad (CPS)" (AFRICAN UNION, 2003, p. 3). La labor del CPS ${ }^{8}$ se verá complementada y apoyada por un Sistema Continental de Alerta Rápida ${ }^{9}$ (CEWS por sus siglas en inglés) y una Fuerza Africana de Despliegue Rápido ${ }^{10}$ (ASF por sus siglas en inglés). La UA reorienta de este modo sus objetivos contraponiéndose a las premisas históricas de su predecesora que a lo largo de toda su existencia se opuso a la injerencia en asuntos internos de los Estados miembros resguardando sus soberanías y situado al Estado por encima de los intereses de la sociedad civil a la que representan. En otras palabras, estamos en presencia de un cambio que suplanta las antiguas convicciones que priorizaban la estabilidad de los Estados y el equilibrio de poder regional e internacional. El principio de no-intervención cede ante la "responsabilidad de proteger" al ciudadano, cuando el Estado no lo garantiza. En tal sentido, la soberanía estatal adopta un carácter restringido o contingente, que abona el intervencionismo para afrontar emergencia política compleja.

Finalmente, el concepto de emergencia política compleja acuñado en la década de los ochenta por Naciones Unidas, o señalado por otros autores como emergencia humanitaria, entendida como "una profunda crisis social donde gran cantidad de personas mueren y sufren la guerra, la enfermedad, el hambre y el desplazamiento debido a desastres naturales y los provocados por el hombre, mientras que otros pueden bene- 
ficiarse de él" (VÄYRYNEN, 1996, p. 19), nos permite observar diferentes sinergias, espacios de cooperación o en otras ocasiones comprender las dificultades surgidas a la luz de lo multifacético de los procesos de paz africanos.

\section{Conclusión}

A lo largo de este trabajo hemos tratado de realizar un análisis historiográfico tratando de exponer los principales lineamientos y reparos a un nuevo corpus teórico que intenta explicar la lógica de los conflictos intra-estatales y sus resoluciones en el África subsahariana.

Los cambios operados en el sistema internacional a partir de la última década del siglo $\mathrm{XX}$, propiciaron el crecimiento y transmutación de los conflictos en la periferia, particularmente en la subregión africana. La clausura de la disputa Este-Oeste y las fuentes de financiamiento vertidas por los dos bloques en pos de garantizar fidelidades y alineamientos, contribuyó a un desequilibrio financiero que redundó en un abrupto achicamiento de las redes clientelares, el colapso operativo de muchos Estados subsaharianos, con el consecuente aumento de los niveles de tensiones y conflictos hacia el interior de los países. Paralelamente, estos conflictos resultan difíciles de comprender si no consideramos su inscripción en un sistema económico global donde los imperativos del capital habla lo suficientemente alto y se valen de las más variadas herramientas en pos de maximizar sus inversiones sin contemplar costos humanos, medioambientales, etc. (DI JOHN, 2002, p. 3-7).
La desideologización de las contiendas, el incremento cuantitativamente más importante de las bajas civiles - ampliamente mayores a la de los soltados y milicias rebeldes actuantes -, la falta de vocación por parte de los movimientos insurgente de acometer la toma del poder - sino por el contrario aspirar como su principal objetivo, al dominio de parte del territorio, garantizándose el control de cierto recurso estratégico en connivencia con el capital internacional - y la incapacidad por parte del Estado de controlar sus territorios - fronteras adentro -, de revertir inequidades sociales y económicas que excluyen a una parte de la población al acceso de sus derechos, beneficiando escandalosamente en otras ocasiones a los más cercanos al poder, son algunas de las características que moldearon a los conflictos subsaharianos, en las últimas tres décadas.

Por su parte, la irrupción del complejo de paz liberal en la resolución de estos conflictos estuvo íntimamente al surgimiento del cosmopolitismo liberal como ideología hegemónica de la comunidad internacional, actuando en detrimento del principio de no injerencia en el ámbito de la soberanía de los Estados nacionales y a favor de un nuevo precepto anclado en el intervencionismo humanitario y la responsabilidad por proteger. De acuerdo a ello, un Estado frente a este nuevo escenario gozará de los derechos internacionales a la integridad territorial y a la soberanía política, sólo en tanto y en cuanto se manifieste como un Estado legítimo desde el punto de vista de la justicia interna, que proteja y garantice los derechos de los sujetos que lo integran. Este nuevo fundamento de la legitimidad y soberanía restringida o 
condicionada del Estado, sustentado en la justicia y los derechos humanos, demandará un gobierno democrático y representativo que promueva la igualdad y la equidad de todos sus ciudadanos. Este discurso hegemónico que ha actuado como norma al momento de intervenir en los países periféricos por parte de la comunidad internacional, ha sido fuertemente criticado por múltiples círculos académicos al sostener que la irrupción del complejo de paz liberal en estas regiones no solo se impone distorsionado los conflictos intra-estatales y los procesos de paz, avasallando el principio de no injerencia en el ámbito de la soberanía de los Estados nacionales, sino que en múltiples ocasiones, de manera eufemística, encubre motivaciones de índole principalmente económicas bajo un discurso de orden humanitario anclado en la "responsabilidad de proteger". Asimismo, la injerencia de organismos regionales en los conflictos intra-estatales africanos, procurando "soluciones africanas para problemas africanos", ha contribuido en la regionalización de muchos conflictos circunscriptos hasta entonces a esferas locales, reconfigurando nuevos escenarios de tensión, cambios de regímenes y liderazgos impuestos desde fuera, no siempre legitimado por los pueblos.

Finalmente, a lo largo de estas páginas hemos tratado de plasmar una importante literatura, que desde diferentes perspectivas, reflexiona acerca de la génesis de los conflictos intra-estatales, su perpetuación y resoluciones; $\mathrm{y}$ atender asimismo, al protagonismo de sus actores tanto en la guerra como en los procesos de paz. No obstante, a nuestro criterio, dicha literatura no conforma aún una teoría, sino más bien un corpus teórico que integra, en sí mismo, divergencias en cuanto a la importancia conferida a ciertos elementos tipificadores de los conflictos y sus resoluciones. En concordancia con lo expuesto, y convencidos de que la construcción de un andamiaje teórico no debe aferrarse a modelos estereotipados que pretendan someter los hechos a la teoría, estimulamos a todo investigador que busque adentrarse a estas problemáticas a que de modo crítico defina su marco teórico o conceptos operativos que le permitan la mejor y más honesta compresión de su objeto de estudio.

\section{Resumo}

Neste artigo, nos propomos colocar à disposição do leitor novas correntes, debates e abordagens conceituais - de uma sólida literatura vinculada às ciências sociais que permitam compreender problemáticas capitais da África subsaariana, como o são os conflitos intraestatais, as emergências políticas complexas, o intervencionismo humanitário e os processos de paz, gestados durante o pós Guerra Fria; portadores de inéditas lógicas e parâmetros guia. Neste sentido, pretendemos observar, através de enfoques contrapostos e em outros casos complementares, diferentes arestas e perspectivas de complexas realidades ao sul do Saara.

Palavras-chave: África subsaariana. Conflitos. Processos de paz. 


\section{Abstract}

In this article we propose to show new tendencies, debates and conceptual approaches - from a solid literature binded to the social sciences - which allow to understand the capital problematics of sub-Saharan Africa, which are the intra-estates conflicts, the emergence of complex politics, the humanitarian interventionism e the peace processes, created during the post Cold War; portraying inedited logics and parameters. We intend to observe, through opposed and in some cases complementary looks, different perspectives of complex realities to the south of Sahara.

Keywords: Sub-Saharan Africa. Conflicts. Peace process.

\section{Notas}

1 A modo de ejemplo: en el caso ruandés, la construcción de un discurso anclado en identidades etnoculturales e impregnado de argumentos estereotipados en la etnicidad, de carácter neocoloniales, etc. que movilizó a la población, no debe introducirnos a la confusión e ignorar una trama mucho más compleja compuesta por intereses económicos de diversos órdenes, inestabilidades en el balance de poder regional e influjos sistémicos que, a nuestro criterio, constituyen las variables explicativas cardinales de las tensiones intra-estatales que desembocaron en el genocidio de abril de 1994.

2 Esta impronta racionalista de las nuevas guerras nos posibilita ahondar en los intereses, motivaciones y objetivos que persiguen los actores envueltos en una espiral de violencia, abstrayéndonos de nociones reductivistas asociadas a un bioculturalismo como en el caso del nuevo barbarismo o de otras propuestas como la del modelo volcánico de las revoluciones y la violencia colectiva (AYA, 1990) que no alcanzan, a nuestro criterio, a explicar con argumentos convincentes esas "explosiones" o "erupciones" de violencia civil.
3 Estos debates vinculados a las nuevas guerras y centrados en la "avaricia" y el "agravio" tuvieron su proyección en el conflicto angoleño. Fundamentalmente, y esto es aquí lo que nos interesa, en la construcción del discurso de ambos contendientes. En tal sentido, el MPLA armó su discurso encorsetando a la UNITA como una organización criminal, cuyas motivaciones estaban circunscriptas a su propio enriquecimiento, no reparando para cumplimentar sus objetivos en abusar de la población civil. A esta visión apegada a la "avaricia", se le contrapuso el discurso que los propios rebeldes contribuyeron a difundir, anclado en elementos identitarios y políticos, argumentando su lucha contra la "agravio" de una élite extranjera -los mestizos o asimilados de MPLA- que estaba robando las riquezas nacionales y mantenía a la población "genuinamente angoleña" en la mas oprobiosa miseria (LE BILLON, 2005, p. 139).

4 Durante los años 60 y 70, el discurso "romántico" orientó las políticas de asilo hacia la acogida, integración y protección de los refugiados. Estos eran identificados como freedom fighters, profundamente politizados, sujetos activos de un cambio percibido como positivo y emancipador, tanto en sus Estados de origen -al subvertir la opresión del orden colonial-, como en las sociedades de acogida (SERRANO MARTÍN, 2012, p. 72). Por el contrario, en los 80 y 90 se asiste a una metamorfosis de su imagen como "víctima" traumatizada por la violencia, actores pasivos políticamente hablando, una "masa" vulnerable merecedora de compasión y asistencia humanitaria. El discurso asociado a la de "seguridad", gestado tempranamente en el siglo XXI, convivirá con el "humanitarista" transformando al "inocente" refugiado en un "criminal" y en una amenaza para la paz y seguridad no sólo para el país de origen sino para el sistema internacional (SERRANO MARTÍN, 2012, p. 72-73).

5 Los campos de refugiado de forma solapada o no, desde la Posguerra Fría sirvieron a las facciones rebeldes como centros irregulares de reclutamiento, en muchos casos gracias a la propia ayuda humanitaria que fue usada como un arma de guerra. Por parte del Estado, se estimuló la cooptación de las víctimas mediante la extorción y el clientelismo, o bajo el discurso de la "seguridad" se los criminalizó, hostigó y despojó de sus derechos como ciudadanos, incrementado con ello la marginación y el agravio de múltiples colectivos los desplazados. En lo atinente a la comunidad internacional mediante su intervención supo convertirse en una "poderosa maquinaria" 
con efectos distorsionadores en las relaciones y dinámicas de los conflictos armados en el continente africano. La irrupción de ONGs y Organismos Internacionales erosionarán las capacidades locales de respuesta estatal; introdujeron una visión del refugiado o los desplazados que privilegia las necesidades por sobre sus derechos. Dichas instituciones y agentes internacionales -que en múltiples ocasiones carecen de un conocimiento cabal de las sociedades donde actúan o de manera igualmente peligrosa reproducen estereotipos falaces acerca de los pueblos africanos- ejercerán un poder de representación sobre los refugiados sin estar sometidos a ningún tipo rendición de cuentas respecto a las poblaciones a las que asisten. Asimismo, múltiples instituciones cooperantes se convirtieran en verdaderos "Señores de la Guerra" (warlords) estableciendo alianzas y potenciando ciertos actores inmersos en los conflictos en desmedro de otros. (BUFFA; BECERRA, 2008).

6 No obstante, el carácter inclusivo de otros actores externos que estas normalmente propusieron, conviene advertir que, la cooperación y el aglutinamiento por detrás de una meta común de los integrantes del complejo de paz liberal, no siempre se manifestó en la praxis.

7 Con la aprobación de una mayoría equivalente a los dos tercios de los votos, sobre el la totalidad de los Estados miembros.

8 Su competencia, de acuerdo a las premisas de su creación, lo facultan a promover peace making y peace building para resolver conflictos cuando éstos ya han ocurrido; autorizar la organización y envío de misiones de apoyo para la paz; recomendar a la Asamblea la intervención, en nombre de la Unión Africana, en un país miembro cuando se presenten crímenes de guerra, genocidio y crímenes contra la humanidad; imponer sanciones cuando se presente un cambio inconstitucional de gobierno; entre otros. (AFRICAN UNION, 2003, p. 11).

9 Operativo desde el 2006, es responsable de la recolección y análisis de datos y tiene el mandato de colaborar con las Naciones Unidas, sus organismos y otras organizaciones internacionales pertinentes. Asesora al Consejo de Paz y Seguridad (CPS), en los posibles conflictos y amenazas a la paz y la seguridad en África, recomendando el mejor curso de acción.

10 En un principio, la UA planeaba tener operativa la ASF en 2008, pero se aplazó primero hasta 2010 y después hasta 2013, y ahora se contempla como fecha 2015. No obstante ello la UA, en estos últimos tiempos ha desplegado sus propias misiones de mantenimiento de la paz en Burundi, Somalia y Sudán. En Burundi (2003), la primera de ellas, la UA desplegó aproximadamente unos 3.335 efectivos de Sudáfrica, Etiopía y Mozambique, al mismo tiempo que contó con observadores militares de Burkina Faso, Gabón, Malí, Togo y Túnez.

\section{Referencias}

AFRICAN UNION. Protocol of Amendments to the Constitutive Act of the African Union. Maputo: African Union, 2003.

AMIN, Samir. El fracaso del desarrollo en África y en el Tercer Mundo. Madrid: IEPALA, 1994.

AYA, Rod. Rethinking Revolutions and Collective Violence: Studies on Concept. Ámsterdam: Theory and Method, Het Spinhuis, 1990.

BADIE, Bertrand. Da soberania à competência do Estado. In: SMOUTS, Marie-Claude (Org.). As novas relações internacionais: teoria e prática. Brasília: Editora da Universidade de Brasília, 2004. p. 35-56.

BECERRA, María José. Angola: hacia la resolución de un largo conflicto. 2006. Tesis (Maestría en Relaciones Internacionales), Universidad Nacional de Córdoba, 2006.

BUFFA, Diego. Conflictos armados intra-estatales y sus resoluciones en la periferia del Sistema Internacional. Un análisis de la guerra y la paz de Angola y Mozambique. 2010. Tesis (Doctodo en Relaciones Internacionales), Universidad Nacional de Rosario, 2010.

BUFFA, Diego; BECERRA, María José. El Intervencionismo Humanitario en África Subsahariana: Actores, instituciones y prácticas bajo un nuevo orden internacional. Ciências $\mathcal{E}$ Letras. v. 44, p. 151-166. 2008.

CILLIERS, Jakkie. Resource Wars - A New Type of Insurgency. In: CILLIERS, Jakkie; DIETRICH, Christian (Ed.). Angola's War Econo$m y$. The Role of Oil and Diamonds. Pretoria: Institute for Security Studies, 2000. p. 1-19. 
CHOPRA, Jarat; WEISS, Thomas. Sovereignty in no longer sacrosanct: codifying Humanitarian Intervention. Ethics and International Affairs. v. 6, p. 95-117, 1992.

COLLIER, Paul. Doing well out of War: an Economic Perspective. In: BERDAL, Mats; MALONE, David (Ed.). Greed and Grievance. Economic Agendas in Civil Wars. Boulder: Lynne Rienner, 2000. p. 91-111.

CRAMER, Chris. The Economics and Political Economy of Conflict in Sub-Saharan Africa. CDPR Discussion Paper 1099. Londres: Centre for Development Policy \& Research, SOAS, 1999.

DI JOHN, Jonathan. Mineral Resource Abundance and Violent Political Conflict: A Critical Assessment of the Rentier State Model. Crisis State Programme: Working Paper 20, 2002. p. 1-20.

DOORNBOS, Martin. State collapse and Fresh Stars: Some Critical Reflections. Development $\mathcal{E}$ Change, v. 33, p. 797-815. 2002.

DUFFIELD, Mark. Las nuevas guerras en el mundo global. La convergencia entre desarrollo y seguridad. Madrid: Ediciones Los Libros de la Catarata, 2004.

ELLIS, Stephen. Interpreting Violence: Reflections on West African Wars. In: WHITEHEAD, Neil. Violence. Oxford: School of American Research Press y James Currey, 2004. pp. 107-124. FRERKS, Georg. The Use of Peace Conditionality in Conflict and Post-Conflict Settings: a conceptual framework and a checklist. The Hague: Netherlands Institute of International Relations, 2006.

FUKUYAMA, Francis. State-building: Governance and Wolrd Order in the 21 st Century. New York: Cornell University Press, 2004.

HOLSTI, Kalevi. The State, War and the State of War. Cambridge: Cambridge University Press, 1996.

KALDOR, Mary. Global Civil Society. An Anwer to War. Cambridge: Polity Press, 2003.
- Las nuevas guerras. Violencia organizada en la Era Global. Barcelona: Tusquets Editores, 2001.

KAPLAN, Robert. The Coming Anarchy: How Scarcity, Crime, Overpopulation, Tribalism and Disease Are Rapidly Destroying the Social Fabric of Our Planet. The Atlantic Magazine. p. 1-58. 1994.

KEEN, David. Incentives and Disincentives for Violence. In: BERDAL, Mats; MALONE, David (Ed.). Greed and Grievance. Economic Agendas in Civil Wars. Boulder: Lynne Rienner, 2000. p. 19-41.

MAMDANI, Mahmood. Darle sentido histórico a la violencia política en el África poscolonial. Revista ISTOR: África, la historia africana en la era de la descolonización. v. 14, p. 48-68. 2003.

PARIS, Roland. Peacebuilding and the limits of liberal internationalism. International Security. v. 2, p. 54-89. 1997.

RICHARDS, Paul. Fighting for the Rain Forest: War, Youth and Resources in Sierra Leone. London: The International African Institute in association with James Currey, 1996.

RUIZ-GIMÉNEZ ARRIETA, Itziar. La nueva agenda de construcción de la paz en África: oportunidades y desafíos. In: MAGALLÓN PORTOLÉS, Carmen (Ed.). África Subsahariana, Continente Ignorado. Zaragoza: Fundación Seminario de Investigación para la Paz, 2011. p. 255-271.

La historia de la intervención humanitaria. El imperialismo altruista. Madrid: Ediciones Los Libros de la Catarata, 2005.

Los conflictos armados del África subsahariana contemporánea. Revista Pueblos. v. 4, p. 31-34. 2002.

SERRANO MARTÍN, María. ¿Héroes, víctimas o criminales?: La evolución de las narrativas y de las políticas hacia los refugiados africanos. In: RUIZ-GIMÉNEZ ARRIETA, Itziar (Ed.). Más allá de la barbarie y la codicia: historia y política en las guerras africanas. Barcelona: Bellaterra, 2012. p. 71-100. 
SINGER, David. Armed Conflict in the Former Colonial Regions: From Classification to Explanation. In: VAN DE GOOR, Luc (Ed.). Between Development and Destruction: An Enquiry into the Causes of Conflict in Post-Colonial States. et al. Washington: MacMillan Press, Houndmills, 1996. p. 35-49.

SNOW, Donald. Uncivil Wars: International Security and the New Internal Conflicts. Londres: Lynne Rienner, 1996.

VÄYRYNEN, Raimo. The Age of Humanitarian Emergencies. Helsinki: The United Nations University-World Institute of Development Economic Research, 1996. 